\title{
The Influence of Social Networks on Team Performance: Moderating Effect of Emotional Contagion
}

\author{
Qian Wang, Xiyan Yu, Hang Yu*, Shan Su, Chunqin Li, Chen Wang, Yinghui Yuan \\ Department of Psychology, Normal College, Qingdao University, Qingdao, China \\ Email: ^iiiyuhang@163.com
}

How to cite this paper: Wang, Q., Yu, X. Y., Yu, H., Su, S., Li, C. Q., Wang, C., \& Yuan, Y. H. (2020). The Influence of Social Networks on Team Performance: Moderating Effect of Emotional Contagion. Open Journal of Social Sciences, 8, 553-565. https://doi.org/10.4236/jss.2020.84040

Received: March 17, 2020

Accepted: April 26, 2020

Published: April 29, 2020*

Copyright $\odot 2020$ by author(s) and Scientific Research Publishing Inc. This work is licensed under the Creative Commons Attribution International License (CC BY 4.0).

http://creativecommons.org/licenses/by/4.0/

(c) (i) Open Access

\begin{abstract}
With the development of the Internet, the use of social networks has become more and more important in team management. The purpose of this study was to investigate the impact of social networks use on team performance and the moderating role of emotional contagion plays in this relationship. 80 college students from 20 innovation and entrepreneurship teams completed questionnaires on team social networks use scale and team performance scale, and then performed team tasks. Three video clips were used as emotionally induced materials. Results showed that the use of social networks can positively predict team performance, and that positive emotional contagion also has the predictive effect. Critically, emotional contagion acts as a moderator in the relationship between the use of social networks and team performance. Specifically, under the condition of positive emotional contagion, the high-level use of social networks can positively predict better team performance; under the condition of negative emotional contagion, there is no significant difference in team performance at different uses of social network service levels. These findings suggest that managers should pay more attention to the dissemination of positive emotional information in social networks to improve team performance.
\end{abstract}

\section{Keywords}

Emotional Contagion, Social Networking Service, Team Performance

\section{Introduction}

With the rapid extension of the Internet and the increasing popularity of social networking platforms, the world has entered the information era (Gong \& Ding, 2020). Nowadays, people can exchange information with global users regardless 
of time and place. Social Networking Service (SNS) is an internet application service designed to help people establish social contact and relationship network (Zhu, 2017). International social network platforms mainly include Twitter and Facebook (Lenhart, Purcell, Smith, \& Zickuhr, 2010), while QQ, WeChat and microblog are wildly popular in China. Social networking platforms can not only help people access social information, but also effectively facilitate organizational management.

By reviewing previous literature, it can be found that numerous studies have explored the use of social networks within enterprises or the individual behaviors of users. The effects of social networks use are mainly focused on two aspects: on the one hand, the social networks can affect individual emotions (Krasnova, Wenninger, Widjaja, \& Buxmann, 2013), interpersonal relationships (Zhao, Gransmuck, \& Martin, 2008), depression (Pantic et al., 2012); on the other hand, the use of enterprise social networks can improve the organizational performance (Yang, 2015), develop and maintain employee relationships (DiMicco, Geyer, Millen, Dugan, \& Brownholtz, 2009).

However, previous research on social networks in organizations has the following defects. Firstly, existing studies exploring the use of social networks in organizations have focused on work-based teams, with less consideration of their impact on team relationships. The use of social networks has great effects on the interpersonal relationship of team members, that is, the frequency of online interaction determines the proficiency of team cooperation and the closeness of member relationship. Limited by cooperation ability and emotional relationship, the intensity of social networks use may affect the team performance of the interpersonal dimension (Nygard, Bender, Walia, Kong, \& Gagneja, 2001). Secondly, social networks contain ample information concerning the emotional expression, which makes it possible for emotional contagion through social networks. Emotional contagion is an automatic and unconscious emotional transmission process between individuals (Hatfield, Cacioppo, \& Rapson, 1993), which is essentially a procedure of imitation. Individuals bring their own unique emotions into the team, and through communication with other members, and then team emotional contagion occurs (Barsad \& Gibson, 1998). In this situation, social network services use and emotional contagion may affect team performance together. However, the previous research on the interaction between the use of social networks and emotional contagion on team performance is very limited. Based on the above two considerations, this study aimed to examine the impact of social networks use and emotional contagion on team performance, and whether emotional contagion plays a moderating role in the relationship between the use of social network service and team performance.

\subsection{Social Network Service Use and Team Performance}

Based on existing research (Ali-Hassan, Nevo, \& Wade, 2015), the using behavior of social networks can be divided into two dimensions: task-oriented social 
networks use (utilize social networks platform to solve the problems at the aspect of work) and relationship-oriented social networks use (encourage each other and talk through social network platform, strengthen emotional relationships).

Social networks determine the quality of team tasks and relationships. Through social networks, employees can broaden their own knowledge volume, promote information sharing within the enterprise, and then resolve existing problems and build organizational membership (Zhao, Yang, \& Xie, 2014). Corporate social networks can help team members better understand, develop and maintain relationships with each other (Dimicco et al., 2009). From an organizational perspective, the use of social software can lead to better performance (Nygard et al., 2011). Therefore, it is a consensus among existing studies that the use of social networks can strengthen the emotional connection between team members, enhance team consciousness and improve team performance.

The first hypothesis was put forward:

H1: There is a significant positive correlation between the use of social networks and team performance.

\subsection{Emotional Contagion and Team Performance}

According to the Affective Events Theory (AET), the emotions caused by work events exert an enormous function on the behaviors and attitudes of organizational members (Weiss \& Cropanzano, 1996). Members bring individual-level affection and emotional experiences to the team for sharing and interact with those of others. Emotional integration can be achieved through emotional contagion and display, (Tang, $\mathrm{Li}, \& \mathrm{Xu}, 2008$ ), which can form collective emotions and affect the efficiency of team tasks. Individuals bring their own unique emotions into the entire team, and then interact with other individuals to cause emotional contagion between teams (Barsade \& Gibson, 1998), at the same time, emotional attention may make influence of emotions bigger (Gong \& Jiao, 2019), the team level emotional state as an essential psychological characteristic of the team will affect team performance (Cohen \& Bailey, 1997). Specifically, teams with more positive emotions tend to share with each other, resulting in more expansive interactions within the team, thereby improving team creativity, internal satisfaction and team learning ability (Rhee, 2007). Substantial research evidence supports the previous theoretical view. For example, Zhang (2013) used ERP (enterprise resource planning) Simulation Game to simulate the actual working scenarios, researching emotions and team members' innovation behaviors, and found that team positive emotions can help team members to discover their potential, while negative emotions can hinder the generation of innovative ideas and behaviors. Huang and $\mathrm{Yu}$ (2016) found that members of the positive emotion team have stronger working ability and get along well with each other within the team, which is conducive to improving the team's relationship performance. Accordingly, the following hypothesis is suggested: 
H2: Emotional contagion has a significant relationship with team performance. Positive emotional contagion positively affects team performance, while negative emotional contagion negatively affects team performance.

\subsection{The Moderating Effect of Emotional Contagion}

In recent years, lots of research on the influence of social networks on emotion has been done by scholars. It has been documented that the emotion expressed by what people post on social media can be contagious. Ferrara and Yang (2015) demonstrated that if people are excessively exposed to positive or negative emotion on Facebook, they will be infected by such emotion. Research on Twitter has also shown a linear correlation between users' positive and negative emotion and their social media exposure. People are much more likely to be affected by positive emotion than negative. Therefore, teams with positive emotion are more likely to ignore the negative impact of low social networks use on team performance, while teams with negative emotions may interfere with better team performance brought about by the high-level use of social networks.

Thus, the following hypotheses were put forward:

H3: Emotional contagion plays a moderating role in the relationship between the use of social networks and the performance of college students' innovation and entrepreneurship team.

H3a: Under the positive emotional contagion, the high-level use of social networks can predict better team performance.

$\mathrm{H} 3 \mathrm{~b}$ : Under the negative emotion contagion, there is no significant difference in team performance between different levels of social networks use.

The conceptual model of this study is shown in Figure 1.

\section{Materials and Method}

\subsection{Participants}

Twenty undergraduate innovation and entrepreneurship teams of 80 students (51 female) recruited from universities in Qingdao, Shandong province, China participated in the experiment. The number of teams was $3-6$, and the subjects were aged from 18 to $23(M=20.59, S D=0.960)$. All data were valid. This study

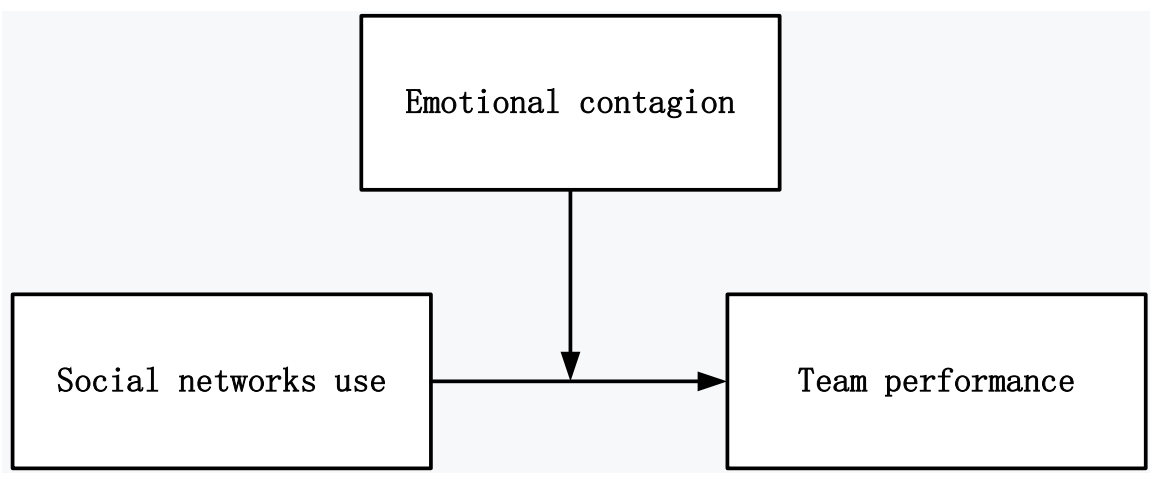

Figure 1. Conceptual model of this study. 
was approved by the Ethical Review Committee of the Department of Psychology, Qingdao University.

\subsection{Instruments}

\subsubsection{Team Social Networks Use Scale}

The team social networks use questionnaire contains two subscales to measure task-oriented and relationship-oriented social networks, respectively. The original questionnaire is in English (Hiller, Day, \& Vance, 2006). Two psychological teachers and one English teacher were involved in translating the questionnaire into Chinese. Then four team members were invited to discuss and revise the detail of the questionnaire to ensure consistency of semantics and content. The inventory consists 24 items in total, 12 in each dimension. Responses to items are indicated on a seven-point Likert scale ranging from 1 (completely inconsistent) to 7 (completely consistent). A higher aggregate score indicates a high-level use of social networks. Cronbach's $\alpha$ of the revised scale was 0.74 for this questionnaire in the present study.

\subsubsection{Team Performance Scale}

It has been demonstrated that the interplay between team members has a significant impact on team performance (Ancona, 1990). Considering the particularity of college student team performance measurement, the present study employed the Team Interaction Process Questionnaire (Liu \& Zhang, 2005) to measure team performance. The inventory consists 9 items in total, 5 for structure performance measurement and 4 for interpersonal performance. Responses to items are indicated on a six-point Likert scale ranging from 1 (total disagree) to 6 (total agree). A higher aggregate score indicates a better team performance. Cronbach's $\alpha$ of this scale was 0.77 in the present study.

\subsection{Emotionally Induced Materials}

The experimental materials are video clips that can elicit positive, neutral and negative emotions respectively.

By referring to the method of Jin et al. (2009), the video materials were collected through questionnaires, and the video editing software Adobe Premiere CC 2018 was used to clip part of the materials to induce emotions. Each video lasted 4 - 6 minutes, and 16 videos were screened after being evaluated by experts. Using the PANAS Emotional Self-Assessment Scale (Watson, Clark, \& Tellegen, 1988; Qiu, Zheng, \& Wang, 2008), 50 college students were randomly selected to evaluate these videos, and the final materials to elicit emotions were obtained. Cronbach's $\alpha$ of the scale was 0.83 and 0.87 .

Pre-experiments showed that: 1) Lecture Power to change the world significantly induced positive emotions of subjects, and generated the effect of positive emotional contagion ( $t=2.68, p<0.05) ; 2)$ short film How wings work had no effect of emotional contagion $(t=-1.29, p>0.05) ; 3)$ film The flowers of war effectively induce the negative emotions and generate the effect of negative emo- 
tion contagion $(t=-2.171, p<0.05)$.

\subsection{Team Tasks}

Leaderless group discussion was adopted as team experimental task, specifically, including the three tasks of Sea rescue, Survival problem, and Leadership trait. All three tasks were asked to be ranked, with similar word counts and no expertise required. Pre-experiments showed no significant difference in time spent on the three tasks.

\subsection{Experimental Design}

The repeated measurement experiment was designed, in which the emotional types (positive emotion, neutral emotion and negative emotion) was treated as a within-subject variable. The dependent variable was team performance.

\subsection{Experimental Procedure}

The experiments were conducted in teams. The subjects were first distributed questionnaires and instruction manuals. The subjects were required to read the brief introduction of the study and matters needing attention, and then to completed the social networks use questionnaire.

The subjects were then presented with an emotion-inducing E-prime program. The flow diagram of experiment is shown in Figure 2.

After the experimental task, participants filled out emotional self-evaluation and team performance questionnaires based on their feelings while watching videos and the completion of team tasks. In order to prevent the mutual influence of different emotions, the Latin order was used to design a balanced sequence effect. Before starting the experiment, the researchers led the team to do leaderless group discussion exercise and conducted 10-minute interactions to ease the participants' tension and familiarize them with the experimental process.

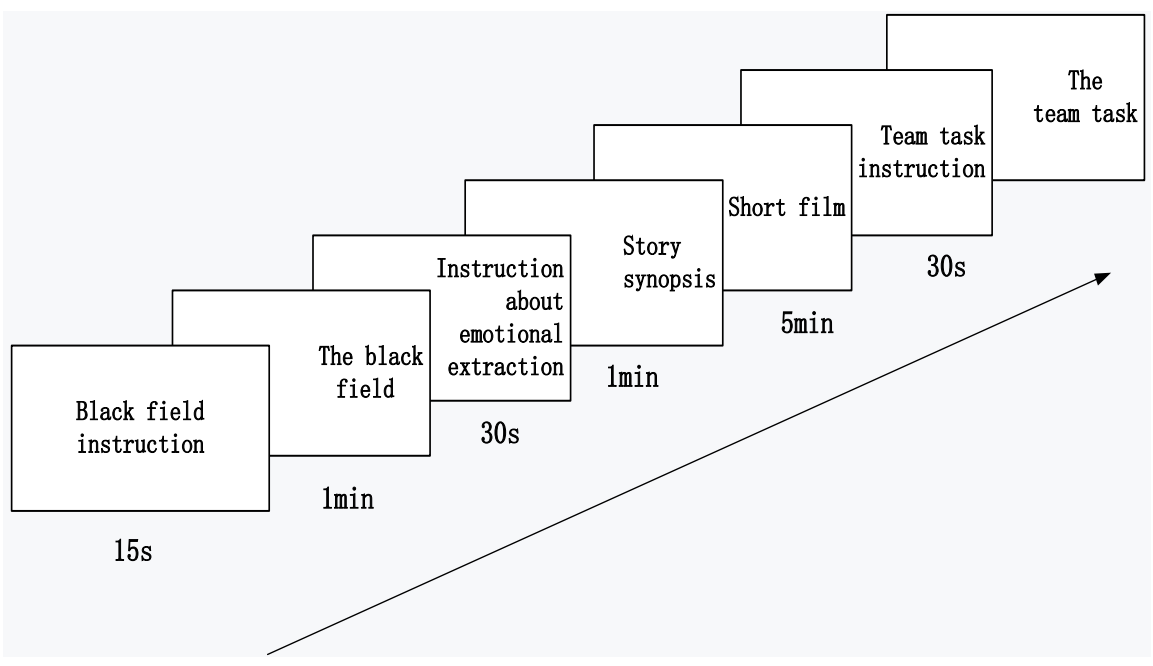

Figure 2. Flow diagram of experiment. 


\section{Results}

\subsection{Descriptive Statistics}

Descriptive statistics and correlation analysis of study variables are shown in Table 1 . There was a significant positive correlation between social networks use and team performance $(r=0.420, p<0.01)$.

\subsection{Regression Analysis of Team Performance on the Social Networks Use}

To investigate the relationship between the use of social networks with different orientations and team performance, a regression analysis was conducted for task-oriented and relationship-oriented social networks use. The analysis results are shown in Table 2.

Results from Table 2, the team performance of task-oriented and relationship-oriented social networks use regression coefficients were significant. The explanation rate $\left(R_{\text {task }}^{2}=0.74\right)$ of task-oriented social networks use for team performance was higher, but the explanation rate $\left(R_{\text {relationship }}^{2}=0.115\right)$ of relationship-oriented social networks use was relatively small. This showed that task-oriented social networks use can significantly predict team performance, while relationship-oriented social networks use has no predictive effect.

\subsection{The Moderating Effect of Emotional Contagion on the Relationship between Social Networks Use and Team Performance}

To investigate whether emotional contagion can moderate the relationship between social networks use and team performance, social network use was divided into three levels on average according to the score of the social networks use scale, namely high, medium and low.

ANOVA with social networks use (high, medium, low) as between-subject factor and emotional contagion (positive, neutral, negative emotion) as within-subject factor revealed a main effect of emotional contagion, $p<0.001$, indicating that

Table 1. Descriptive statistics and correlation analysis.

\begin{tabular}{lccc}
\hline & $M$ & $S D$ & Social networks use \\
\hline Social networks use & 120.35 & 5.995 & \\
Team performance & 37.17 & 6.43 & $0.42^{\star *}$ \\
\hline
\end{tabular}

Note: ${ }^{\star} p<0.05,{ }^{* *} p<0.01,{ }^{* *} p<0.001$, same as below.

Table 2. Regression analysis results of team performance on the social networks use.

\begin{tabular}{ccccc}
\hline The independent variables & $B(S E)$ & $\beta$ & $t$ & $R^{2}$ \\
\hline Task-oriented social networks use & $0.498(0.114)$ & 0.272 & $4.335^{\star * *}$ & 0.74 \\
Relationship-oriented social networks use & $0.471(0.85)$ & 0.339 & $5.552^{* * *}$ & 0.115 \\
\hline
\end{tabular}

Note: $B$ is the unstandardized regression coefficient, and $\beta$ is the standardized regression coefficient, same as below. 
the team performance with different emotional contagion is significantly different. Critically, the interaction between social networks use and emotional was significant, $p<0.001$, which suggests that emotional contagion acts as a moderator between social networks use and team performance. Further analyses revealed under positive emotional contagion $(F=42.984, p<0.001)$ and non-emotional contagion $(F=36.200, p<0.01)$, social networks use has a significant impact on team performance; under negative emotional contagion, team performance at different social networks levels was not significantly different ( $F$ $=1.708, p>0.05)$. Among them, the average of team performance under positive emotions was the highest $(M=43.33)$. Therefore, under positive emotional contagion, high-level social networks use can predict high-level team performance; under the negative emotional contagion, there was no significant difference in team performance between different levels of social networks use. The specific data of the ANOVA are shown in Table 3 , and the specific moderate patterns are shown in Figure 3.

\section{Discussion}

This study examined the association between social networks use and team performance, as well as the moderating role of emotional contagion. These results

Table 3. Moderating effect of emotional contagion in the relationship between social networks use and team performance.

\begin{tabular}{cccc}
\hline Variable & $d f$ & $M S$ & $F$ \\
\hline Social networks use & 2 & 590.140 & $61.317^{\star * *}$ \\
Emotional contagion & 2 & 3185.483 & $330.980^{* * *}$ \\
Social networks use $\times$ emotional contagion & 4 & 94.197 & $9.787^{* * *}$ \\
\hline
\end{tabular}

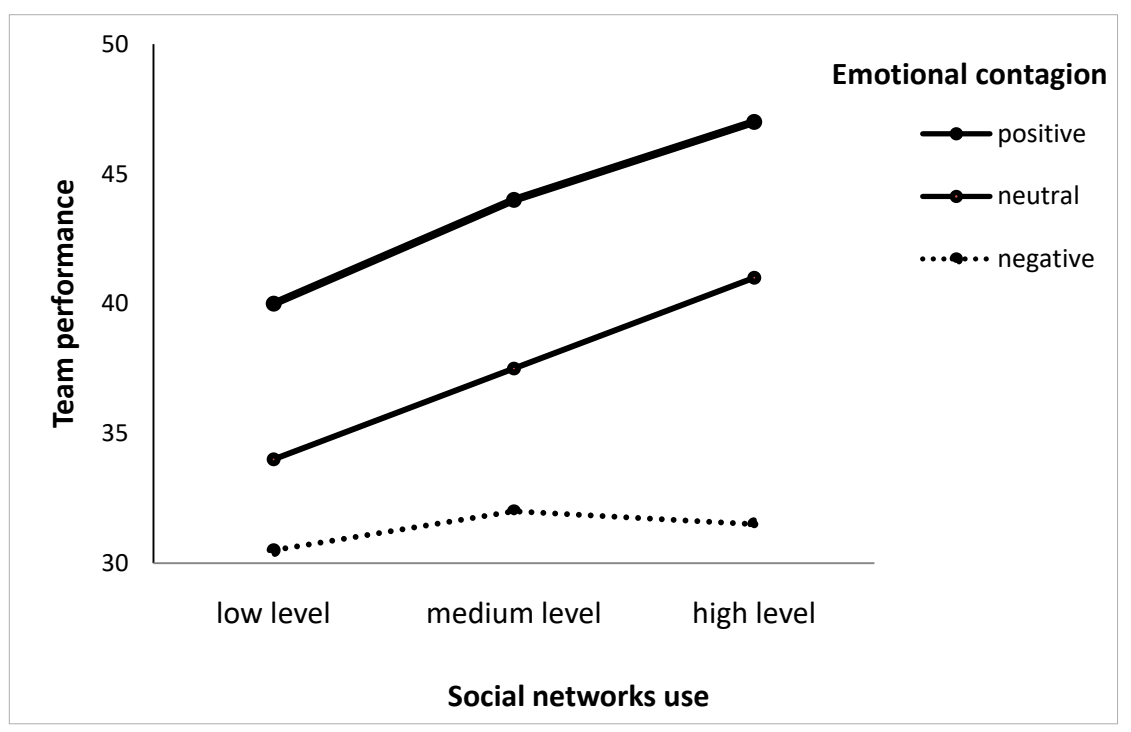

Figure 3. The moderating effect of emotional contagion on social networks use and team performance. 
showed that social network use is positively correlated with team performance. Compared with relationship-oriented social networks use, task-oriented social networks use can predict team performance effectively. Emotional contagion acts as a moderator in the relationship between social networks use and team performance. Specifically, under positive emotional contagion, high level of social network use can predict better team performance.

Consistent with previous research, social networks use can positively predict team performance. As mentioned above, according to Nygard et al. (2011), high level of social networks service use enables team members to understand each other, thereby promoting team consciousness and predicting team performance. These results also demonstrated that correct and appropriate use of social networks is not only an essential factor to improve team performance, but also an important way to build a good relationships, improve team consciousness, enhance innovation ability and develop talent (Gong, 2016).

It was found that relationship-oriented social networks use has no significant predictive effect on team performance, which is in line with the previous study of Ali-hassan (2015). Task-oriented social networks use can improve the innovative performance of teams, while relationship-oriented social networks use has a mitigation effect on team performance. Both task-oriented and relationship-oriented social networks use are social behaviors aiming to promote team building, but their purposes are different. Task-oriented social network use is conducive to the completion of team tasks so that the solution of team tasks can be practiced in daily social network use. Relationship-oriented social networks use can facilitate the formation of affection relationships among team members. In this sense, task-oriented social networks use and team performance share positive factors, while relationship-oriented social networks use does not. Therefore, task-oriented social networks use is strongly correlated with team performance, while relationship-oriented social networks use is weakly correlated with it.

Another important question that the study focused on was whether emotional contagion could moderate the relationship between social networks use and team performance. Research has shown that high level of social network use can predict better team performance under positive emotional contagion condition. According to the extended construction theory of positive emotions, positive emotions can expand individuals' cognition and action, and improve their development and processing skills (Fredrickson, 2004). Studies have shown that employees can manage emotions by adjusting their perception of the work environment and the emotional stimuli from the environment, gain positive emotions (Gong, Chen, \& Wang, 2019). Employees' positive emotions can affect their job burnout through the role of psychological warfare mediators (Gong, Schooler, Wang, \& Tao, 2018). Individuals with positive emotions have a high degree of work engagement, more flexible thinking and higher work efficiency. In addition, positive emotions make individuals take a positive attitude towards others and the environment, and they are more willing to support each other and enhance interpersonal relationships. Therefore, when the team is in a state 
of positive emotions, the team members are more capable of working and have a friendly relationship with each other, which helps to improve team performance. Besides, positive emotions positively affect self-affirmation and reduce anxiety (Gong, Yu, \& Schooler, 2018). The study also found that there was no significant difference in team performance between different levels of social network use under the condition of negative emotional contagion. In contrast, negative emotions will promote the systematic and detailed way of information processing, to narrow the scope of individual attention, limit the divergent thinking, obstruct the cognitive way of exploration type, thereby weakening its creativity (Liu \& Liu, 2012). The negative emotions of members will impair team performance.

The results of this study provide guidance for managers in team management. At the same time, researchers should pay attention to the role of positive emotion contagion in the connection between the use of social networks and team performance, so as to improve team performance by spreading positive emotion information in social networks.

\section{Conclusion}

This study investigated the effects of social networks use, emotional contagion and their interactions on team performance. Results demonstrated that social networks use has a positive impact on team performance, that is, the greater the intensity of social networks use, the higher the team performance. In addition, emotional contagion is significantly related with team performance. Positive emotional contagion can significantly improve team performance, while negative emotional contagion can impair team performance. Critically, emotional contagion plays a moderating role between social networks use and team performance. Specifically, under the condition of positive emotion contagion, high level of social networks use can predict better team performance. In contrast, under the condition of negative emotion contagion, there was no significant difference in team performance between different levels of social network use. These findings demonstrate the importance of spreading positive emotional information in social networks to improve team performance.

\section{Funding}

This work was supported by grants from the National Social Science Fund of China under Grant No. 14CGL073 and Shandong Social Science Planning Research Project under Grant No. 18CRCJ01.

\section{Informed Consent}

Informed consent was obtained from all individual participants included in the study.

\section{Ethical Approval}

All procedures performed in studies involving human participants were in ac- 
cordance with the ethical standards of the institutional and/or national research committee and with the 1964 Helsinki declaration and its later amendments or comparable ethical standards.

\section{Conflicts of Interest}

The authors declare that they have no conflict of interest.

\section{References}

Ali-Hassan, H., Nevo, D., \& Wade, M. (2015). Linking Dimensions of Social Media Use to Job Performance: The Role of Social Capital. The Journal of Strategic Information Systems, 24, 65-89. https://doi.org/10.1016/j.jsis.2015.03.001

Ancona, D. G. (1990). Outward Bound: Strategic for Team Survival in an Organization. Academy of Management Journal, 33, 334-365. https://doi.org/10.5465/256328

Barsade, S. G., \& Gibson, D. E. (1998). Group Emotion: A View from Top and Bottom. Research on Managing Groups and Teams, 1, 81-102.

Cohen, S. G., \& Bailey, D. E. (1997). What Makes Teams Work: Group Effectiveness Research from the Shop Floor to the Executive Suite. Journal of Management, 23, 239-290. https://doi.org/10.1177/014920639702300303

Dimicco, J. M., Geyer, W., Millen, D. R., Dugan, C., \& Brownholtz, B. (2009). People Sensemaking and Relationship Building on an Enterprise Social Network Site. In 42nd Hawaii International Conference on Systems Science (HICSS-42 2009), Proceedings (CD-ROM and Online). Los Alamitos, CA: IEEE Computer Society.

Ferrara, E., \& Yang, Z. (2015). Measuring Emotional Contagion in Social Media. PLoS ONE, 10, e0142390. https://doi.org/10.1371/journal.pone.0142390

Fredrickson, B. L. (2004). The Role of Positive Emotions in Positive Psychology: The Broaden-and-Build Theory of Positive Emotions. Philosophical Transaction of the Royal Society B, 359, 1367-1377. https://doi.org/10.1098/rstb.2004.1512

Gong, Z. (2016). Management of Human Resources: From the Perspective of Government and Public Management. Beijing: China Social Science Press. (In Chinese)

Gong, Z., \& Ding, Y. (2020). Design and Implementation of Wearable Dynamic Electrocardiograph Real-Time Monitoring Terminal. IEEE Access, 8, 6575-6582.

https://doi.org/10.1109/ACCESS.2019.2958992

Gong, Z., \& Jiao, X. (2019). Are Effect Sizes in Emotional Intelligence Field Declining? A Meta-Meta Analysis. Frontiers in Psychology, 10, 1655. https://doi.org/10.3389/fpsyg.2019.01655

Gong, Z., Chen, Y., \& Wang, Y. (2019). The Influence of Emotional Intelligence on Job Burnout and Job Performance: Mediating Effect of Psychological Capital. Frontiers in Psychology, 10, 2707. https://doi.org/10.3389/fpsyg.2019.02707

Gong, Z., Jonathan, W. S., Wang, Y., \& Tao, M. (2018). Research on the Relationship between Positive Emotions, Psychological Capital and Job Burnout in Enterprises' Employees: Based on the Broaden-and-Build Theory of Positive Emotions. Canadian Social Science, 14, 42-48.

Gong, Z., Yu, L., \& Schooler, J. W. (2018). The Relationship between Resilience and Mental Health: The Mediating Effect of Positive Emotions. https://doi.org/10.22158/asir.v2n3p87

Hatfield, E., Cacioppo, J. T., \& Rapson, R. L. (1993). Emotional Contagion. Current Directions in Psychological Science, 2, 96-100. 
https://doi.org/10.1111/1467-8721.ep10770953

Hiller, N. J., Day, D. V., \& Vance, R. J. (2006). Collective Enactment of Leadership Roles and Team Effectiveness: A Field Study. The Leadership Quarterly, 17, 387-397. https://doi.org/10.1016/j.leaqua.2006.04.004

Huang, Y. F., \& Yu, W. (2016). Team Knowledge Sharing Structure and Team Performance-Mediating Effect of Team Emotion. Journal of Information, 35, 166-172. (In Chinese)

Jin, X., Deng, G. H., Jing, M., \& Lin, G. Z. (2009). The Effect Evaluation of Video Material to Induce Emotion. Psychology Exploration, 29, 83-87. (In Chinese)

Krasnova, H., Wenninger, H., Widjaja, T., \& Buxmann, P. (2013). Envy on Facebook: A Hidden Threat to Users' Life Satisfaction? In International Conference on Wirtschaftsinformatik (Vol. 92, pp. 1-16). Leipzig, Germany.

Lenhart, A., Purcell, K., Smith, A., \& Zickuhr, K. (2010). Social Media \& Mobile Internet Use among Teens and Young Adults. Millennials. Pew Internet \& American Life Project, 51, 14-15.

Liu, X. F., \& Zhang, Z. X. (2005). Preliminary Study and Measurement of Team Member Interaction in Simulated Situation. Acta Psychologica Sinica, 37, 253-259. (In Chinese)

Liu, X. Y., \& Liu, J. (2012). The Influence Mechanism of Team Emotional Atmosphere on Team Innovation Performance. Acta Psychologica Sinica, 44, 546-557. (In Chinese) https://doi.org/10.3724/SP.J.1041.2012.00546

Nygard, K. E., Bender, L., Walia, G., Kong, J., Gagneja, K., \& LeNoue, M. (2011). Collaboration Using Social Networks for Team Projects. In The International Conference on Frontiers in Education: Computer Science and Computer Engineering (Vol. 11, pp. 86-92). Las Vegas, Nevada.

Pantic, I., Damjanovic, A., Todorovic, J., Topalovic, D., Bojovicjovic, D., Ristic, S. et al. (2012). Association between Online Social Networking and Depression in High School Students: Behavioral Physiology Viewpoint. Psychiatria Danubina, 24, 90-93.

Qiu, L., Zheng, X., \& Wang, Y. F. (2008). Revision of the Positive and Negative Emotion Scale (PANAS). Chinese Journal of Applied Psychology, 14, 249-254. (In Chinese)

Rhee, S. Y. (2007). Shared Emotions and Group Effectiveness: The Role of Broadening-and-Building Interactions. The Academy of Management Journal, 50, 605-622.

Tang, C. Y., Li, G. J., \& Xu, L. C. (2008). Review and Prospect of Team Emotion Research. Advances in Psychological Science, 16, 926-932. (In Chinese)

Watson, D., Clark, L. A., \& Tellegen, A. (1988). Development and Validation of Brief Measures of Positive and Negative Affect: The PANAS Scales. Journal of Personality and Social Psychology, 54, 1063-1070. https://doi.org/10.3724/SP.J.1041.2012.00546

Weiss, H. M., \& Cropanzano, R. (1996). Affective Events Theory: A Theoretical Discussion of the Structure, Causes and Consequences of Affective Experiences at Work. Research in Organizational Behavior, 18, 1-74.

Yang, T. (2015). Research on the Theory and Practice of Enterprise Social Network. China High Technology Enterprises, 25, 162-163. (In Chinese)

Zhang, M. (2013). An Empirical Study on the Influence of Constructive Debate and Team Emotion on Team Members' Innovation Behavior. Science \& Technology Progress and Policy, 30, 144-148. (In Chinese)

Zhao, S., Grasmuck, S., \& Martin, J. (2008). Identity Construction on Facebook: Digital Empowerment in Anchored Relationships. Computers in Human Behavior, 24, 1816-1836. https://doi.org/10.1016/j.chb.2008.02.012

Zhao, Y., Yang, G., \& Xie, C. Y. (2014). Research on the Influence of SNA Social Media 
on Enterprise Knowledge Sharing. Finance and Economics, 10, 92-101. (In Chinese)

Zhu, X. W., \& E, Y. T. (2017). An Empirical Analysis of the Influence of the Use of Social Network Service Platform on the Social Capital of College Students. Journal of Xi'an Jiaotong University, 37, 79-87. (In Chinese) 